\title{
A atuação dos psicólogos em Unidades de Saúde da Família: Relações entre Gênero Profissional e saúde
}

Lucas Có Barros Duarte. Universidade Federal do Espírito Santo.

Thiago Drumond Moraes. Universidade Federal do Espírito Santo.

\section{Resumo}

Esse estudo se propõe a descrever as percepções que os psicólogos têm acerca das atividades de trabalho que desenvolvem nas Unidades de Saúde da Família (USF) e os efeitos do trabalho percebidos por esses profissionais em sua saúde. Para tanto, utilizase a análise da atividade de trabalho do psicólogo em serviços de APS, inspirando-se nas abordagens da Ergonomia francesa e da Clínica da Atividade. Foram realizados cinco encontros com seis psicólogas de USF e empregada a técnica de instrução ao sósia com três participantes desse grupo. Os encontros e as instruções ao sósia foram gravados, e os conteúdos foram analisados por meio da análise do discurso. Discute-se a fragilidade do coletivo e do Gênero Profissional de psicólogos atuantes em USF, acarretando na atuação solitária e consequente dificuldade para lidar com as demandas e os desafios do cotidiano de trabalho, bem como o impacto na saúde desses trabalhadores.

Palavras-chave: saúde ocupacional; atuação do psicólogo; serviços de saúde pública.

\begin{abstract}
The performance of psychologists in Family Health Units: Relations between Professional Gender and health. This study aims to describe the perceptions that psychologists have about the work activities they develop in Family Health Units (FHU) and the effects from work perceived by these professionals on their health. In order to do so, we analyzed the work activity of the psychologist in PHC services, drawing on the approaches of the French Ergonomics and Clinic of the Activity. We held five meetings with six FHU psychologists and applied the instruction to the double technique with three participants of this group. We recorded the meetings and instructions to the double and analyzed the data with discourse analysis. We discuss the fragility of the collective and of the Professional Gender of psychologists working in FHU, resulting in solitary action and consequent difficulty in dealing with the demands and challenges of daily work, as well as the impact it has on these worker's health.
\end{abstract}

Keywords: occupational health; psychologist performance; public health services.

\section{Resumen}

El desempeño de los psicólogos en las Unidades de Salud de la Familia: Relaciones entre el Género Profesional y la salud. Este estudio se propone describir las percepciones que los psicólogos tienen acerca de las actividades de trabajo que desarrollan en las Unidades de Salud de la Familia (USF) y los efectos del trabajo percibidos por esos profesionales en su salud. Para ello, se utiliza el análisis de la actividad de trabajo del psicólogo en servicios de APS, inspirándose en los enfoques de la Ergonomía francesa y de la Clínica de la Actividad. Se realizaron cinco encuentros con seis psicólogas de USF y empleada la técnica de instrucción al sósia con tres participantes de ese grupo. Los encuentros y las instrucciones al sósia fueron grabados, y los contenidos fueron analizados por medio del análisis del discurso. Se discute la fragilidad del colectivo y del Género Profesional de psicólogos actuantes en USF, acarreando en la actuación solitaria y consecuente dificultad para lidiar con las demandas y los desafíos del cotidiano de trabajo, así como el impacto en la salud de esos trabajadores.

Palabras clave: salud ocupacional; actuación del psicólogo; servicios de salud pública. 
Nos últimos anos, o campo de atuação da psicologia tem se ampliado, superando os tradicionais campos da psicoterapia, recrutamento e seleção, educação e magistério (Dimenstein, 1998). Essa ampliação se dá, principalmente, devido à inserção do psicólogo em serviços públicos e políticas públicas, como de saúde e de assistência social. Ao se inserirem nesses novos campos, os psicólogos encontram uma série de desafios, sobretudo quanto à dissonância entre a formação obtida nos cursos de graduação e às demandas encontradas nesses serviços (Boarini \& Borges, 2009; Romagnoli, 2009; Sales \& Dimenstein, 2009). Assim, cabe aos profissionais elaborarem novos modos de atuação para atenderem tais demandas. Entretanto, essa empreitada nem sempre se passa incólume.

É nessa direção que Duarte e Moraes (2016) constatam relações entre o trabalho e a saúde mental dos psicólogos que atuam na Atenção Primária à Saúde (APS). Segundo os autores, a configuração de trabalho desses psicólogos apresenta um alto nível de controle e uma alta demanda psicológica do trabalho. Essa caracterização relacionou-se significativamente com um elevado índice de adoecimento mental e baixa qualidade de vida. Os autores não investigaram, porém, a que aspectos do trabalho esses adoecimentos estão relacionados. Diante de tal quadro, ainda insuficientemente estudado, é relevante compreender as nuances da atividade de trabalho e seus impactos na saúde do trabalhador.

Jimenez (2011) afirma que o percurso do profissional de psicologia nos serviços de APS teve início na década de 1980, com o reconhecimento da complexidade e da dimensão da saúde mental pela Organização Mundial de Saúde (OMS) e por conta dos movimentos da Reforma Sanitária e da Reforma Psiquiátrica no Brasil. Inicialmente, a atuação do psicólogo nesses espaços se restringiu à saúde mental, com uma atuação baseada principalmente no atendimento clínico individual. Posteriormente, com a implementação do Sistema Único de Saúde, diversas críticas e questionamentos foram levantados acerca do trabalho do psicólogo na APS, por se avaliar que esse tipo de atuação não contemplava os princípios do SUS.

Destaca-se a inserção do psicólogo nos serviços de APS mais especificamente a partir da implementação do Programa Saúde da Família (PSF) (Cardoso, 2002). O PSF é definido pelo Ministério da Saúde [MS] como uma estratégia que "visa à reorganização da Atenção Básica [uma das formas mais usuais de se referir a APS no
Brasil] no País, de acordo com os preceitos do Sistema Único de Saúde" (MS, 2012, p. 54), buscando expandir, qualificar e consolidar esse nível da atenção à saúde. Para isso, reorganiza os processos de trabalho nos serviços de saúde, definindo uma atuação coletiva por meio de equipes multiprofissionais. O psicólogo se insere como parte da equipe de apoio, nos Núcleos de Apoio à Saúde da Família (NASF), atuando de forma integrada às equipes de PSF (MS, 2012). Entretanto, é um desafio para o trabalho da Psicologia a mudança nos modos de atuação, ainda pautada numa atuação individualizada e clínica (Costa \& Olivo, 2009).

A existência de distintos modos de atuação nos serviços de saúde não é uma questão exclusiva do trabalho do psicólogo. Souza (2014) sugere que a diferenciação dos conceitos de Saúde Pública e Saúde Coletiva relacionam-se a movimentos ideológicos diferentes que influenciam na atividade dos trabalhadores de saúde. A Saúde Pública caracteriza-se por uma concepção biologista, focada nos problemas de saúde, doenças e agravos, enquanto a Saúde Coletiva prioriza ações de promoção e prevenção que objetivam atender as necessidades de saúde. $\mathrm{O}$ autor aponta a manutenção de tal distinção na atual sociedade, estando a Saúde Pública mais frequentemente institucionalizada nas atividades quotidianas dos serviços do SUS, ao passo que a Saúde Coletiva, ainda que tenha inspirado o projeto da Reforma Sanitária e ao SUS, persiste como alternativa contra-hegemônica (Souza, 2014).

\section{Pressupostos teórico-epistemológicos orientadores da pesquisa}

A Ergonomia se desenvolveu por meio de duas escolas principais: a Ergonomia anglo-saxônica ou clássica, com foco nos métodos e nas tecnologias, se importando com as características físicas da relação do homem com o trabalho; e a Ergonomia francesa ou contemporânea, que preconiza uma análise da atividade, tendo como cerne do seu interesse a atividade de trabalho (Almeida, 2011; Guérin, Laville, Daniellou, Douraffourg, \& Kerguelen, 2001). A vertente da escola francófona é a adotada nesse trabalho.

Guérin et al. (2001) apontam para as relações entre atividade, desempenho e saúde. Para os autores, vários aspectos envolvidos na realização do trabalho se influenciam mutuamente e estão relacionados ao processo de saúde e doença: os "objetivos" exigidos, sejam eles gerais (fixados pela empresa), intermediários

Estudos de Psicologia, 23(2), abril a junho de 2018, 99-110 
(fixados pelo próprio trabalhador e pelos coletivos para atingir os fixados pela empresa), ou pessoais (objetivos auto impostos, como ter reconhecimento pelo trabalho feito, aumentar o salário, conseguir descansar durante o trabalho); os "resultados" esperados pela organização ao final do trabalho; os "meios" que o trabalhador dispõe para desenvolver a atividade; o "estado interno" do trabalhador, referente a características biológicas do organismo, o raciocínio e os saberes adquiridos, a personalidade e os projetos individuais; as "regulações", referentes ao modo como o trabalhador se (re)organiza mediante a relação com os fatores anteriores, de acordo com a margem de manobra da qual dispõe; e os "modos operatórios", caracterizados como "um conjunto de compromissos provenientes de níveis diferentes" (Guérin et al., 2001, p. 67).

De modo geral, sugere-se que os modos operatórios devem ser executados a partir da possibilidade das regulações dos trabalhadores atuarem sobre os objetivos (tarefas e expectativas) e meios (instrumentos) para atingir os resultados sem que percam de vista seu estado interno. Por exemplo: se a demanda de um serviço aumenta, ou mudam os instrumentos - atendimento em grupo no lugar de individual -, ou mudam os objetivos - fazer terapias breves no lugar de psicoterapias longas -, visando garantir que os resultados esperados e o estado interno continuem considerados na equação. Caso não seja possível alterar os objetivos e meios, retira-se muito da margem de manobra dos trabalhadores, aumentando a carga de trabalho e, consequentemente, a ansiedade. Ao longo do tempo, a redução da margem de manobra pode acarretar doença e, consequentemente, na própria possibilidade de o trabalhador atingir os resultados esperados.

A partir das contribuições da Clínica da Atividade (Clot, 2006), propõe-se nesse estudo a adição do conceito de Gênero Profissional aos fatores anteriormente apresentados. Clot formulou a abordagem teórica que embasa a Clínica da Atividade (Clot, 2010) pela qual propõe a análise do real da atividade de trabalho, buscando desenvolvê-la junto aos trabalhadores, visando à ampliação do poder de ação e o fortalecimento dos coletivos de trabalho. A partir dos estudos de Bakhtin, Clot e Faïta desenvolveram o conceito de Gênero Profissional, entendido como o "intermediário sociossimbólico", o interlocutor entre o trabalhador e a atividade de trabalho, funcionando como uma fonte de recursos à qual o trabalhador se remete para realizar sua atividade. Ele possibilita ao trabalhador acessar a história de gerações de profissionais que trabalharam nessa atividade, com seus problemas, soluções, dificuldades e invenções (Clot, 2010). Com esse entendimento, insere-se o conceito de Gênero Profissional como o conjunto de "regulações" e "modos operatórios" dos trabalhadores. O Gênero Profissional é composto a partir do compartilhamento das "regulações" e dos "modos operatórios" no coletivo, possibilitando aos trabalhadores a antecipação do fazer diante dos conflitos subjacentes à realização da atividade.

Desse modo, evidenciam-se as possíveis relações entre desempenho, atividade e saúde do trabalhador e Gênero Profissional. Clot afirma que "na ausência de previsíveis genéricos disponíveis, pode-se mostrar que a saúde se degrada no ambiente de trabalho" (2010, p. 170). Assim, em uma situação de trabalho em que o Gênero está ausente ou é enfraquecido, o trabalhador tem uma margem de manobra menor, resultando num poder de ação reduzido. Isso, segundo Clot, pode acarretar o adoecimento pelo trabalho.

Apesar de a literatura reconhecer a longa e controversa trajetória da saúde pública e coletiva no país, são escassos estudos investigando as relações entre o trabalho dos psicólogos nesse ambiente e os processos saúde-doença. O objetivo da presente pesquisa foi descrever as percepções dos psicólogos acerca das atividades de trabalho que desenvolvem nas Unidades de Saúde da Família (USF) e os efeitos do trabalho na saúde percebidos por esses profissionais. Para tanto, utiliza-se a análise da atividade de trabalho do psicólogo em serviços de APS, inspirando-se nas abordagens da Ergonomia francesa e da Clínica da Atividade.

\section{Método}

Essa pesquisa inspirou-se na lógica do compreender $\leftrightarrow$ transformar (Guérin et al., 2001), própria da análise ergonômica da atividade, para analisar o trabalho de psicólogos atuantes em serviços de APS, especificamente em USF. A pesquisa foi proposta com base na escassa literatura sobre o trabalho de psicólogos na APS e em "pistas" de que esses trabalhadores estariam adoecendo devido ao trabalho, como indicado por alguns profissionais em conversas informais. A proposta de um espaço coletivo de análise e transformação da atividade de trabalho está fundada nos pressupostos das teorias de referência.

Partiu-se do entendimento que "qualquer dispositivo para compreender $\leftrightarrow$ transformar o trabalho em 
sua dinâmica com a saúde deve ser, sempre que possível, uma operação de coanálise" (Ramminger, Athayde, \& Brito, 2013, p. 3192), garantindo a um grupo de trabalhadores a organização de um espaço coletivo que possibilite não apenas a emissão de informações sobre as experiências e do cotidiano de trabalho, mas uma verdadeira análise coletiva sobre suas atividades. Para tanto, utilizou-se a técnica proposta pela Clínica da Atividade, conforme descrito a seguir. A esses espaços de coanálise dá-se o nome de Comunidade Ampliada de Pesquisa, dispositivo formulado por Brito e Athayde (2003), com base na leitura crítica desenvolvida por Yves Schwartz sobre a concepção de Comunidade Científica Ampliada.

Os pesquisadores elaboraram e submeteram o projeto para avaliação pela Escola Técnica de Saúde (ETSUS) do município e pelo Comitê de Ética em Pesquisa. Após as devidas aprovações, o pesquisador dirigiu-se às USF, no intuito de apresentar a pesquisa aos diretores e solicitar a liberação das psicólogas para participarem dos encontros. Depois da liberação das profissionais por alguns diretores, iniciou-se o trabalho de organização do coletivo, agendando-se a data e o horário do primeiro encontro com as profissionais.

Participaram dos encontros seis psicólogas trabalhadoras de USF, dentre as quais quatro já atuavam nos serviços há pelo menos cinco anos e duas há dois anos. Os encontros foram realizados em uma USF, escoIhida pelas próprias participantes. Houve um total de cinco encontros, organizados para propiciar a produção de um debate e uma análise entre as trabalhadoras a respeito das atividades que desenvolvem enquanto psicólogas de USF.

No primeiro encontro apenas duas psicólogas estiveram presentes, o que dificultou o desenvolvimento do trabalho inicialmente proposto. No segundo encontro, que contou com a presença das seis psicólogas, foi realizada uma apresentação da pesquisa e da perspectiva teórico-metodológica adotada, esclarecendo questões a respeito dos objetivos e do andamento dos grupos. Do segundo encontro em diante, buscou-se dialogar com as profissionais, fazendo com que apresentassem e debatessem as atividades que realizam, visando compreender as relações entre o trabalho e a saúde dessas psicólogas. Os debates coletivos foram suscitados a partir de temas sugeridos pelos pesquisadores ou pelas trabalhadoras.

Entre as questões discutidas com as trabalhadoras no decorrer dos encontros estão: condições de trabalho nas quais realizam as atividades; constrangimentos a que estão submetidas; exigências e demandas profissionais; relações com os demais trabalhadores do serviço; o que pensam que deveriam fazer enquanto psicólogas em unidades de saúde; o que não conseguem fazer; entre outras. Além disso, na quinta, e última, data as psicólogas compartilharam as análises que fizeram a partir dos encontros anteriores e de uma técnica utilizada para enriquecer a análise do trabalho.

Além desses temas, para contribuir com as reflexões coletivas sobre a atividade e, sobretudo, sobre o Gênero Profissional, optou-se pelo uso da técnica de instrução ao sósia (Oddone, Re, \& Briante, 1981), a partir das adaptações propostas pela Clínica da Atividade (Clot, 2006; 2010). A técnica de instrução ao sósia consiste numa intervenção em que, num primeiro momento, o pesquisador se dirige ao trabalhador, individualmente, com o seguinte questionamento: "suponha que eu seja seu sósia e que amanhã eu deva substituir você em seu trabalho. Que instruções você deveria me transmitir para que ninguém perceba a substituição?" (Clot, 2006, p. 144).

No segundo momento da técnica o trabalhador é confrontado com o diálogo resultante desse questionamento, sobre o qual deve realizar uma análise. Para isso, ele tem acesso ao áudio contendo a gravação da primeira etapa, a fim de que sejam produzidas análises sobre a sua atividade de trabalho (Clot, 2006). Depois dessa etapa, abre-se ao coletivo as análises individualmente realizadas. Na presente pesquisa, essa técnica foi realizada com quatro profissionais, nas suas respectivas unidades de saúde, antes do último encontro, garantindo a análise coletiva sobre a experiência no último encontro com as profissionais.

Ao utilizar essa técnica e esse modo de intervenção, esperava-se conhecer as percepções das psicólogas acerca das atividades de trabalho que realizam, e seus possíveis efeitos na saúde. Ao mesmo tempo, proporcionou-se um espaço de elaboração de um patrimônio coletivo acerca do trabalho que realizam, ou seja, de compartilhamento de estratégias utilizadas para enfrentar os constrangimentos encontrados na realização do trabalho, por meio de regulações e modos operatórios próprios. Assim, de acordo com as próprias participantes, esse espaço coletivo, proporcionado por essa pesquisa, oportunizou a discussão de questões que muitas vezes não emergem no cotidiano de trabalho, ou que o trabalhador não dispõe de tempo suficiente para refletir a respeito. Através das discussões, diferentes

Estudos de Psicologia, 23(2), abril a junho de 2018, 99-110 
olhares acerca dessas questões possibilitaram um rico debate, potencializando mudanças na percepção e no fazer dos agentes envolvidos no grupo, ainda que, por impossibilidade temporal, não se pode dar sequência às etapas de discussão sobre as transformações de fato ocorridas no cotidiano.

Tanto as instruções ao sósia como os encontros foram gravados em áudio, sendo esse material gravado analisado sob a perspectiva da análise do discurso. Os áudios dos encontros serviram de auxílio ao pesquisador para as análises produzidas posteriormente às realizações dos encontros. Ademais, ao final do último encontro fez-se uma primeira validação, juntamente com as trabalhadoras, de todo o trabalho desenvolvido durante a pesquisa.

Ressalta-se a inspiração no trabalho de Daniel Faïta (2005), acerca das análises da atividade profissional a partir do diálogo com os trabalhadores, baseando-se na hipótese de Bakhtin. A análise do discurso implica a compreensão do texto simultaneamente em três dimensões: o intratexto, o intertexto e o contexto (Macedo, Larocca, Chaves, \& Mazza, 2008), com o objetivo de entender as práticas discursivas, relações de poder estabelecidas e as nuances do contexto originário do discurso. Atenta-se, então, não apenas ao conteúdo explícito do texto, mas àquilo que está implícito, ou seja, a "procedência da fonte, indagações efetuadas, inserção na sociedade, condições de produção, verificação dos destinatários, o não-dito, a veracidade do texto e as contradições percebidas" (Macedo et al., 2008, p. 653). Buscou-se, com isso, estabelecer uma construção da narrativa a partir do que foi trazido nos encontros e nas instruções ao sósia, verificando-se as relações entre os processos de trabalho-saúde-doença, elucidadas nos discursos das psicólogas, num movimento de coanálise.

\section{Resultados e discussão}

A partir dos encontros coletivos com as profissionais e das aplicações da técnica de instrução ao sósia, foi possível observar a pluralidade de discursos presentes na prática do(a) psicólogo(a) na Atenção Básica. Ora esses discursos se aproximam, demonstrando afinidades entre as profissionais, ora se distanciam, elucidando um embate entre os modos de saber-fazer da psicologia nesse espaço. Segundo as psicólogas, nos serviços de Atenção Básica do município estudado, há psicólogos atuando em funções distintas. A recente implantação dos Núcleos de Apoio à Saúde da Família (NASF) faz com que coexistam nos serviços alguns psicólogos atuando nas equipes de NASF e outros atuando como psicólogos das USF. Apesar de as duas funções apresentarem semelhanças, psicólogos no NASF têm como principal tarefa prestar apoio matricial às equipes de saúde da Atenção Básica. Matriciamento, ou apoio matricial, se refere ao apoio técnico pedagógico e assistencial na condução de casos realizados por equipes de unidades especializadas em saúde às equipes da Atenção Básica (Chiaverini, 2011). Ademais, os NASF "não são de livre acesso para atendimento individual e coletivo" (MS, 2012, p. 69), diferentemente dos psicólogos da USF, que atuam majoritariamente com atendimentos, individuais ou coletivos, à população.

Durante os encontros, alguns problemas foram recorrentemente trazidos à discussão coletiva: a diversidade das tarefas; a amplitude das demandas para atuação; a relação com os colegas das equipes das USF; os conflitos vivenciados no cotidiano de trabalho; sistemas de controle sobre a produtividade do psicólogo; os impactos das relações de trabalho na saúde das psicólogas. A fim de melhor compreendê-los, sintetiza-se a seguir a maneira como as psicólogas descreveram o cenário em que suas atividades se desenrolam.

As psicólogas relataram diversas tarefas ao discutirem acerca do trabalho que realizam, como: atendimento individual; atendimento em grupo; grupo de acolhimento; reuniões de equipe; oficinas; discussão de caso; visita domiciliar; matriciamento; tarefas administrativas (preencher prontuário, bater ponto, acessar sistema eletrônico); relações com outros aparelhos (encaminhamentos); entre outras. Destaca-se que parte expressiva das tarefas refere-se a atribuições relacionadas ao trabalho partilhado com outros profissionais (reuniões de equipe, discussão de caso, matriciamento, relações com outros serviços), enquanto outras tarefas são mais usualmente atribuídas aos psicólogos (atendimento individual e/ou em grupo e oficinas).

À amplitude de tarefas soma-se a complexidade das demandas dirigidas às profissionais. São demandas provenientes dos usuários: "[Os usuários] criticam o funcionamento da unidade. Querem que aqui seja PA (Pronto Atendimento)" (Psicólogo 1 (P.1)). Segundo as psicólogas, "a população busca um atendimento psicológico a partir de um discurso que é criado em torno do psicólogo (focado no atendimento individual)" (P.3), acarretando em uma demanda insaciável: "Tem um limite de quanto a gente consegue atender. A gente 
não dá conta daquilo ali. Não dá pra gente trazer todo mundo pra dentro. 'Vamos atender todo mundo!', como algumas pessoas querem" (P.2).

São demandas recebidas, também, por encaminhamento de outros profissionais que, segundo elas, "às vezes [...] tem uma expectativa bem irreal do trabalho do psicólogo" (P.2). À incompreensão da população sobre o trabalho das psicólogas soma-se as percepções imprecisas de seu ofício por parte dos próprios colegas da unidade: "a maior questão que a gente se debate lá dentro da unidade é isso. Você tem que se afirmar como profissional generalista, mas a equipe entende que você é um especialista dentro da unidade" (P.3).

Mas há, também, as demandas menos relacionadas ao cuidado com os usuários, tais como aquelas provenientes dos níveis hierárquicos de gestão da Política de Saúde Mental do município, que exigem das psicólogas, sobretudo, o trabalho de "sensibilizar" os demais profissionais frente aos casos de saúde mental.

P.1: Essas questões da saúde mental deveriam atravessar todos os treinamentos, de enfermeiro, de médico. [...] Porque senão fica como responsabilidade do psicólogo. Trabalhar isso na unidade. [...] Não pode entrar nessa ideia de que nós aqui temos que mudar a cultura. É uma responsabilidade, uma pressão, uma coisa difícil.

\section{P. 2: Sensibilizar! Eu tenho raiva dessa palavra.}

É possível perceber como as psicólogas problematizam a responsabilidade pela mudança de postura dos colegas, frente à temática e aos atendimentos de pacientes da saúde mental, implícita nesse "trabalho de sensibilizar". As psicólogas sentem-se incumbidas de contribuir para a mudança de concepção dos profissionais da equipe a respeito da doença mental, por meio da discussão de casos e proposição de outros encaminhamentos às demandas de atendimentos individuais recebidas. No entanto, não reconhecem essa "sensibilização" como algo que devem realizar solitariamente, entendendo que seria necessário o apoio dos profissionais de referência da Saúde Mental da Secretaria de Saúde nesse tipo de trabalho.

A responsabilização por esse trabalho de "sensibilizar os colegas" não é exclusiva dos níveis gerenciais da política de saúde mental municipal, mas também é auto imposta pelas profissionais. A autodeterminação dessa tarefa se produziu historicamente a partir de diversos pontos de origem: os movimentos da reforma sanitária; a militância da psicologia na luta antimanicomial e na reforma psiquiátrica; os espaços de troca com outros profissionais da saúde mental; a formação que essas psicólogas obtiveram nos cursos de graduação etc.

Por fim, há as demandas dos diretores das USF em que trabalham, que frequentemente preocupam-se mais pela quantidade de atendimentos: "Eu falei [com a diretora], 'olha, eu estou perdida. A orientação que eu tive na reunião do NASF foi essa [só atender depois de passar pela equipe], e agora você está me falando isso. Eu respondo a quem?" (P.3). Destaca-se a percepção de desconforto diante da ambiguidade de tarefas.

Ao se referirem às relações com os demais profissionais das unidades de saúde, as trabalhadoras caracterizam como difíceis, pois muitas vezes elas necessitam estabelecer laços afetivos, de amizade, para conseguir desenvolver trabalhos coletivos, em detrimento da problematização de questões políticas, econômicas, sociais e morais: "o olhar do psicólogo não dá certo com outros profissionais. [...] Os profissionais não prestam muita atenção nos casos de saúde mental" (P.5); "você até consegue dialogar [na unidade], mas não com essa qualidade [a percebida nos encontros da pesquisa]" (P.3). Caso não abdiquem de suas problematizações e posicionamentos, sentem dificuldade em desenvolver o trabalho, restando uma atuação solitária (intelectual e fisicamente): "é como se a gente fosse engolido por essa massa dominante. Que tem essa forma de pensamento, essa forma de trabalhar" (P.4).

Diversos conflitos foram relatados pelas profissionais nos encontros. Conflitos referentes aos modelos assistenciais em saúde, que coexistem no serviço, refletindo em demandas contraditórias da gestão (principalmente diretores das USF e Secretaria de Saúde); conflitos teóricos com os demais profissionais; e conflitos com as demandas dos usuários.

Até nessa questão agora de tentativa de implantação do NASF, que muda o processo de trabalho do psicólogo, já tem todo um "cabo de guerra" interno dentro da Secretaria.

[...] O NASF faz um movimento, a secretaria faz outro, internamente. Então se você ousa falar em mudança de agenda, mudança de processo de trabalho do psicólogo, já não tem tanta aceitação. Imagina falar em adoecimento [referindo-se ao tema da pesquisa]. (P.3)

Foi relatada a importância dada pelos diretores, área técnica e gestores ao sistema de avaliação quantitativa do desempenho - número de atendimentos (individuais ou em grupo) realizados - levando o trabalhador 
a um ritmo de trabalho acelerado que não permite nem mesmo uma "pausa para beber água" (P.2; P.6). Diversos instrumentos foram citados como forma de controle do trabalho: o ponto eletrônico, que deve ser registrado quatro vezes ao dia; o prontuário eletrônico, por meio do qual se tem acesso à agenda, onde se registram os atendimentos e se tem acesso a informativos e comunicados dos serviços da rede; a agenda de atendimentos, sobre a qual muitas profissionais relataram não ter controle, enquanto algumas disseram ter "certo controle", mas não podendo "fechar demais". Sobre o próprio trabaIho, avaliam que "tem certa autonomia, mas não é total. Primeiro, pro que ela [a diretora da unidade] acha que tem que ser o serviço. Segundo, porque a Secretaria [de Saúde] está num momento de cobrar mais procedimentos. Isso significa mais atendimentos individuais" (P.3).

Ainda que as demandas sejam voltadas mais frequentemente ao atendimento individual de usuários, foram relatadas atividades mais ligadas ao modelo de promoção e prevenção. Entre elas, discussão coletiva de casos com os demais profissionais das equipes de saúde; participação nas reuniões de equipe; apoio às equipes, sobretudo com relação aos casos de saúde mental; atendimento compartilhado com outros profissionais; trabalhos em grupo, sem caráter ambulatorial, como oficinas com idosos, adolescentes, grupo antitabagismo, etc.

Depreende-se da descrição dessas informações a existência de um conflito, nos serviços de saúde entre dois modelos assistenciais (Sales \& Dimenstein, 2009), duas lógicas aqui denominadas Saúde Pública e Saúde Coletiva (Souza, 2014). A não resolução desse conflito por parte dos instrumentos gerenciais e políticos aliada à contínua delegação da incumbência da sua superação a alguns profissionais, acarreta sofrimento nesses profissionais que devem atuar conforme os novos modelos de atuação promulgados pelo referencial da Saúde Coletiva.

P.3: Quando eu falo disso, eu lembro do meu cansaço. Do como é cansativo por eu estar fazendo isso [a tarefa de representar a política de saúde mental na unidade] sozinha.

P.2: O que eu acho mais adoecedor [...] é a falta de apoio de quem está acima de nós. A área técnica de saúde mental, a Secretaria [de Saúde] de maneira geral.

P.1: As próprias pessoas que coordenam na Saúde Mental adoeceram. É um sofrimento geral.
Essas ideias são corroboradas por Gomes (2009), que ao discutir sobre os desafios enfrentados pelos trabalhadores atuantes em serviços de PSF, observa que muitos acabam sendo responsabilizados ou sentindo-se responsáveis por mudar o modelo assistencial de atenção à saúde. $O$ autor afirma que é exigida desses trabaIhadores uma mobilização intensa visando implementar novos modelos de atenção no cotidiano, embora contando com um arcabouço normativo frágil e insuficientemente capaz de orientá-los em suas práticas habituais, para fazer frente às imposições gerenciais na qual ainda predominam normatizações relativas ao modelo a ser superado. Como exemplo, podemos citar os sistemas de avaliação da produção, ainda fortemente calcadas em números de atendimentos individuais, conforme preconiza o modelo de Saúde Pública, mesmo que o modelo de Saúde Coletiva incentive o aumento de atendimentos em grupo. Gomes destaca ainda a relação entre tal realidade e o sofrimento dos trabalhadores, ao observar que os Agentes Comunitários de Saúde (ACS), ou "Agentes da Mudança", são considerados os "super-heróis" responsáveis pela efetivação da política de saúde proposta pelo SUS, sendo que "essa superestimação do trabalho dos agentes é uma potencial fonte de adoecimento para estes trabalhadores" (2009, p. 134).

No relato das psicólogas é evidenciado esse conflito, sobretudo entre os profissionais dos serviços de porta de entrada, como as USF. A ambiguidade de exigências é oriunda dos diversos níveis gerenciais: a direção da unidade, a área técnica de saúde mental e a Secretaria de Saúde em geral. A gestão ora demanda do psicólogo um trabalho mais quantitativo, focado no sintoma, na clínica individualizada e na resolução de casos, ou seja, um trabalho de especialista; ora exige que ele atue mais próximo às equipes, exercendo um papel de apoio e "sensibilização" dos outros profissionais frente à saúde mental.

Ainda que não claramente explicitadas como tarefas formalizadas, entende-se que essas demandas assumem, por conta da hierarquia do serviço, um papel de prescrição para os trabalhadores, ou seja, determinam as tarefas informais a serem realizadas pelos psicólogos nesses serviços. A conotação de tarefa é ainda mais evidente diante da incerteza quanto ao trabalho que é formalmente esperado delas, uma vez que estão ausentes diretrizes claras de ação ou prescrições exatas para o cotidiano, e devido à ambiguidade das orientações e normatizações. As psicólogas relatam, por exemplo, que a única prescrição de tarefa sobre 
a qual têm conhecimento é a determinação para que $40 \%$ da agenda do psicólogo seja destinada a atividades denominadas "atendimento individual" e 60\% para atividades voltadas para o "trabalho em grupo". No entanto, também não se sabe precisar quais atividades são consideradas como "atendimento individual" ou como "trabalho em grupo".

P.3: Na gestão passada foi pactuado $40 \%$ para atendimento individual.

\section{P.1: São 60\% de grupo e 40\% individual.}

P.4: E aí a gente fica sem saber direito o que a gente realmente tem que fazer.

P.2: Acho que ninguém sabe direito. Nem a gente sabe direito, nem a gestão sabe direito.

Desse modo, frente à ausência de tarefas formais, os psicólogos precisam atender às demandas antagônicas da gestão e dos demais profissionais, gerando ambiguidade na compreensão e realização do serviço. Como relata uma psicóloga, o trabalho é "meio que no improviso", o que causa angústia por não conseguir lidar com as diferentes demandas.
Com relação ao reconhecimento que as psicólogas têm a respeito das atividades que desenvolvem, percebeu-se ao longo dos encontros que não há um consenso sobre quais seriam as tarefas desempenhadas, apesar de reconhecerem boa parte das tarefas enquanto trabalho do psicólogo. Destaca-se, nesse ponto, o atendimento individual, que mesmo sendo a atividade mais demandada e mais associada ao trabalho do psicólogo, é vista como tomando um tempo excessivo do dia a dia de trabalho. No entendimento das profissionais, elas deveriam se dedicar mais a outras atividades nas unidades, de caráter coletivo, e ter menos tempo da agenda destinado a esse tipo de atendimento.

Também relacionado ao atendimento individual, as psicólogas disseram que são orientadas a atender as chamadas "demanda espontânea", ou seja, quando o usuário busca diretamente o atendimento psicológico sem passar por um acolhimento ou ter um encaminhamento. As profissionais deixam claro que atender a esse tipo de demanda não condiz com o espaço da unidade, uma vez que o foco nesse tipo de atendimento se opõe ao modelo preconizado pelo PSF (Gomes, 2009): "O trabalho do psicólogo não se resume ao atendimento ambulatorial, [...] antes de qualquer coisa, nós não somos equipe mínima, nós somos apoio. Nossa agenda não pode ser igual à do médico" (P.3).

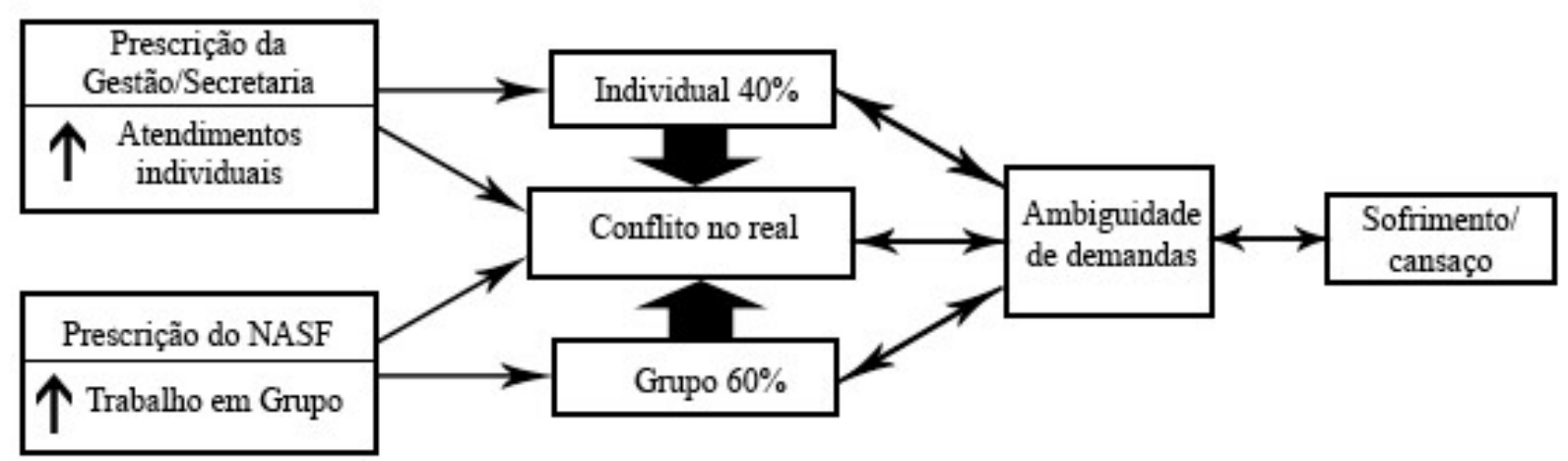

Figura 1. Ambiguidade da Prescrição do Trabalho do Psicólogo em USF e o Sofrimento desses Trabalhadores.

A Figura 1 ilustra um esquema de como essas demandas de atuação, voltadas a interesses diferentes e pautadas em pressupostos distintos, geram, mediante os conflitos vivenciados no real, uma situação de sofrimento, cansaço e adoecimento, como relatado pelas psicólogas. $O$ acordo firmado estabelece que $40 \%$ do trabalho do psicólogo destina-se a atendimentos individuais. Entretanto, há um crescimento na demanda por esse tipo de atendimento e uma valorização do quantitativo de atendimentos por parte dos diretores das USF e da Secretaria. Por outro lado, o município adere à implantação de NASF, aumentando a demanda para o trabalho em grupo, pautado no apoio às equipes de saúde da família. O aumento dessas demandas é, de certo modo, contraditório, gerando um conflito para o trabalhador ao realizar sua atividade. Mediante esse 
conflito e sem encontrar soluções, potencializa-se o risco de adoecimento, o que impacta a qualidade de seu serviço e os modos de regular esses conflitos, alterando a proporção de atendimentos individuais ou coletivos.

Além da ambiguidade existente nas demandas advindas das gerências e departamentos da Secretaria de Saúde (Figura 1), há conflitos que ocorrem junto às equipes de saúde da unidade. Durante as instruções ao sósia, a tarefa mais relatada pelas profissionais foi a reunião de equipe do PSF, abordada em todas as conversas. Diversos apontamentos foram feitos a respeito das reuniões, como a relação com os colegas, o modo como os demais profissionais entendem os casos de saúde mental, o que esses profissionais demandam e esperam da atuação do psicólogo, o conteúdo dos casos discutidos durante as reuniões, entre outros.

As psicólogas destacaram que, durante as reuniões de equipe, necessitam "bancar uma postura", no sentido de exercer uma militância frente às demandas advindas dos colegas, e promover uma atuação mais próxima à lógica da Saúde Coletiva, - numa função de apoio às equipes, voltada para o coletivo, com foco em atividades de prevenção e promoção à saúde - e não da Saúde Pública, como requisitado pelos outros profissionais.
Nas discussões de casos durante as reuniões de equipe geram-se situações de confronto, tanto de ideias como de posturas: "A solidão que mais pesa é esse embate, da gente estar sozinho nessa nova clínica. Tendo que afirmar o tempo inteiro" (P.5). Com isso o psicólogo se vê "solitário intelectualmente", por ser, muitas das vezes, o único a optar por atuar nessa lógica diferente.

Eu sinto uma solidão intelectual muito grande. Porque se algumas coisas eu posso falar, usando esses termos que estou falando com você, e aí quando eu consigo falar com um par [psicólogo], eu falo disso com facilidade. Quando eu vou falar com outro colega, eu tenho que escolher as palavras. Como eu vou falar e o que eu vou falar. Porque tem que se ter cuidado (P.3).

Os constantes confrontos de lógicas da saúde e a percepção de solidão nesse enfrentamento contribuem para que a reunião seja um espaço de embates de saberes que, longe de ser revigorante, conduz a cansaço e, frequentemente, sofrimento entre as psicólogas (Figura 2). As profissionais relatam exaustão e esgotamento após as reuniões, e algumas ainda precisam fazer atendimentos individuais antes de encerrarem sua jornada de trabalho.

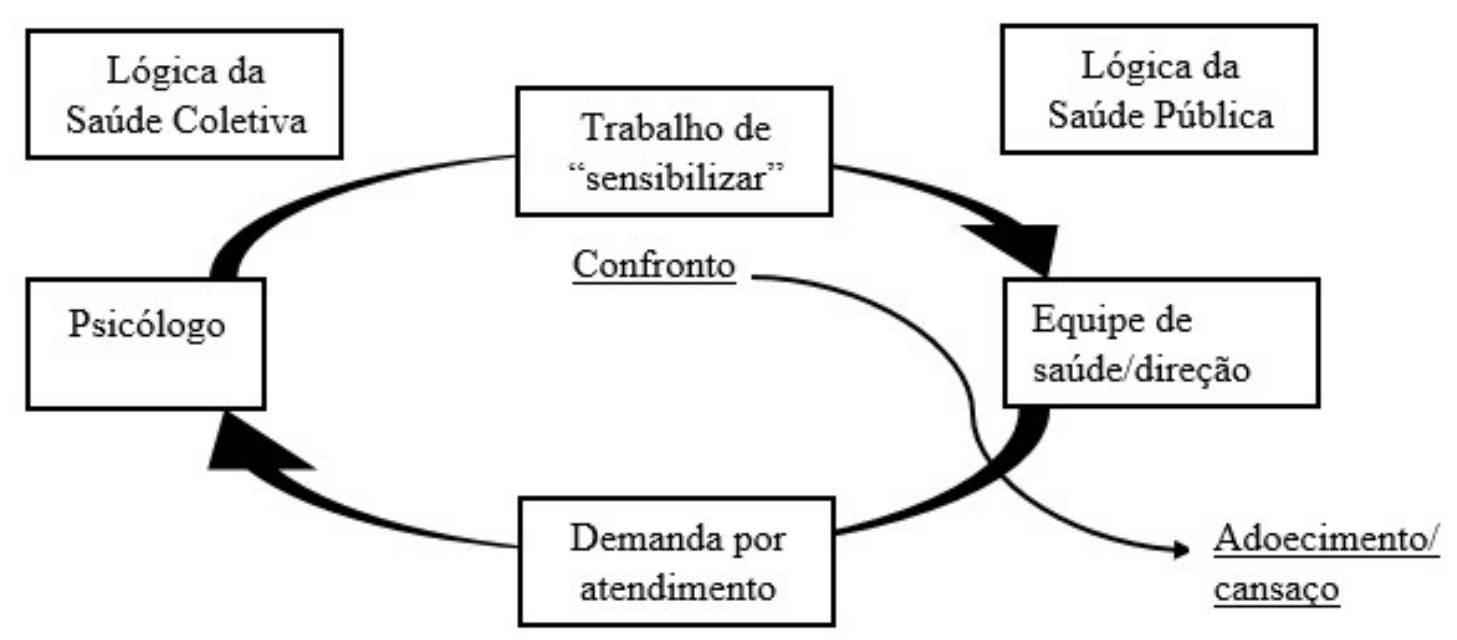

Figura 2. Atuação do Psicólogo em Modelos Assistenciais Distintos.

Por fim, evidenciou-se ao longo dos encontros e das discussões entre as psicólogas, pistas que nos levaram a inferir a ausência ou a presença de um Gênero Profissional bastante fragilizado para atuação delas. Tais pistas foram frutos da coanálise das questões levantadas, sobretudo nos debates envolvendo as psicólogas atuantes há menos tempo no serviço. Como afirma Clot, o Gênero Profissional é um "conjunto de avaliações compartilhadas" (2010, p. 122), que orienta a atividade do profissional de modo que não "seja necessário reespecificar a tarefa a cada vez que ela se apresenta" (p. 122). Assim, o Gênero permite ao trabalhador, mesmo aquele mais recente no exercício da atividade, antecipar-se à ação, além de fornecer um arcabouço de instrumentos para lidar com os imprevistos impostos pelo real. 
Eu vejo colegas vivendo uma lógica que eu não sei se é por opção deles, ou se é por pressão da Secretaria. [...] Quando eu vi as meninas falando que já chegaram a fazer 15 atendimentos num dia, 50 por semana, eu falei 'Não gente. Tem alguma coisa errada. O que está acontecendo?' [..] Eu fiquei assustada. Não sei se elas estão sendo obrigadas, ou se elas realmente acham que tem que ser $\operatorname{assim}$ (P.3).

Pôde-se notar a partir das falas das psicólogas que devido às situações de trabalho em que atuam nas USF, há um enfraquecimento da construção desse saber coletivo da atividade. As dificuldades encontradas para realizar encontros e reuniões que possibilitem esse compartilhamento de avaliações, fragilizam o coletivo e, logo, o Gênero Profissional.

Em meio a um embate de modelos assistenciais, saberes distintos, normas ambíguas, elas tendem a se ver solitárias e isoladas, buscando superar individualmente os obstáculos para realizar tarefas. Essas estratégias são elaboradas, muitas vezes, por meio de tentativa e erro e da leitura individual das demandas e do espaço de trabalho, ou seja, são bastante pessoais. Nota-se que há dificuldade inclusive em lidar com os conflitos com os demais trabalhadores, sendo estabelecidas alianças afetivas em vez de acordos profissionais: "O médico confia na minha avaliação. Eu tenho muita sorte com a minha equipe. [...] Eu tenho certa reputação de uma boa profissional aqui, então as pessoas respeitam a minha opinião. Não tem problema em trabalhar comigo" (P.2).

Essa condição, vivenciada pelas psicólogas, remete ao paradoxo de viver entre a inflação e ausência de normas que Brito, Muniz, Santorum e Ramminger (2011) identificaram a respeito dos desafios encontrados pelos profissionais em serviços de saúde. Os autores destacaram o paradoxo entre uma inflação e uma ausência de normas, implícitas e explícitas, comumente vivenciada por profissionais em que as prescrições não são claramente expostas ou deveras ambíguas, frente à grande variabilidade de situações a serem vivenciadas e sem uma orientação clara para auxiliar nos problemas cotidianamente enfrentados. Tal paradoxo demanda do trabalhador uma implicação maior na atividade, se tornando, de certa forma, mais arriscada e podendo levar ao adoecimento. Essas situações de adoecimento estão relacionadas, ainda, como os autores destacam, a uma fragilidade do Gênero Profissional e à falta de respaldo institucional. Esse parece ser o caso dessas profissionais de psicologia, que partindo de uma formação de militância, adotam posturas de atuação que divergem dos demais profissionais da equipe, fragilizando o coletivo de trabalho e acarretando num fazer solitário.

Considerando que a inserção do psicólogo na APS é relativamente recente e ainda são escassas as discussões a respeito dessa atuação nos cursos de graduação (Boarini \& Borges, 2009; Romagnoli, 2009; Sales \& Dimenstein, 2009), deduz-se que o Gênero de psicólogo nesses serviços de Atenção Primária se configuraria num novo Gênero, razão pela qual apresenta certa fragilidade. Aliado a isso, as próprias condições do trabalho dificultam seu fortalecimento, uma vez que o compartilhamento dos saberes e das histórias experienciadas pelos psicólogos tem dificuldade de se concretizar devido à raridade de momentos que possibilitem esse tipo de diálogo. As participantes relataram que num momento anterior havia reuniões com todos os psicólogos dos serviços de saúde mental do município, no entanto, com a mudança da gestão, deixaram de acontecer, distanciando os profissionais.

Por outro lado, como a resolução dos impasses impostos pela realidade requer conhecimentos ou estratégias que de um modo ou de outro estão disponíveis, as psicólogas se apropriam ou tomam de empréstimo saberes e avaliações de outros Gêneros. Esses Gêneros podem estar relacionados a outras realidades de trabaIho, como a de psicólogo clínico, ou a outros profissionais, como o Gênero do médico, do enfermeiro ou do assistente social. Outra possibilidade seria uma orientação genérica mais ampla, englobando a atividade de diversos profissionais de saúde, como um Gênero dos profissionais dos serviços de APS, entre outros.

O que nos parece mais evidente é que, nesse processo transicional entre modelos de atenção à saúde e de efetivação das prerrogativas do SUS, o espaço dos serviços de saúde se torna um território fértil para o desenvolvimento de novos Gêneros e estilos profissionais. Ressalta-se que esses Gêneros podem ser ora intercessores, ora conflitantes, ou até mesmo complementares, a depender das dinâmicas estabelecidas nas situações de trabalho. É importante lembrar que o Gênero está sempre em desenvolvimento, encontrando nas estilizações e no conflito com o real a possibilidade para se aprimorar.

A fragilidade de um Gênero decorre do seu enrijecimento ou da falta de compartilhamento dentro do coletivo, sendo que o Gênero em uma dessas condições pode ser um fator determinante para o adoecimento dos profissionais (Clot, 2006; 2010). Sem ter esse saber compartilhado sobre a atividade, o trabalhador encontra-se em uma situação na qual deverá dispor apenas

Estudos de Psicologia, 23(2), abril a junho de 2018, 99-110 
de suas regulações para elaborar novos modos operatórios que lhe permitam desempenhar suas atividades. Ao realizar seu trabalho de maneira "solitária", com um arcabouço limitado de instrumentos para a ação, é exigido do trabalhador um dispêndio muito maior de energia e tempo, ocasionando um maior desgaste e cansaço, podendo acarretar, por fim, no adoecimento do profissional.

\section{Conclusões}

Observa-se nos discursos que surgiram ao longo dos encontros, a fragilidade no coletivo devido, sobretudo, à ausência de momentos de troca de experiências e diálogos a respeito do trabalho realizado no dia a dia. Desse modo, os psicólogos da rede municipal encontram-se limitados a atuar de maneira solitária, dentro das suas respectivas unidades de saúde, sem maiores possibilidades de troca com os demais colegas de profissão dos serviços.

Infere-se que dentre os problemas enfrentados por psicólogos na atuação em USF encontram-se não apenas o saber o que fazer, já que elas aparentam ter algum conhecimento, apesar da ambiguidade das demandas e da diversidade de tarefas relatadas, mas, sobretudo, o saber como fazer o necessário. As profissionais não parecem dispor de modos operatórios, normas antecedentes ou orientações advindas de um Gênero Profissional, que possibilitem a atuação dentro do que elas próprias e/ou os outros esperam.

Podem-se elencar algumas possibilidades de compartilhamento de modos operatórios e consequente fortalecimento do Gênero Profissional, visando uma atuação menos adoecedora para os psicólogos nos serviços de saúde. Dentre essas possibilidades, sugerem-se: formação continuada, que possibilite a atualização no sentido técnico da atuação; espaços de reuniões e debates coletivos, tanto com profissionais da mesma categoria como com profissionais do mesmo serviço, fomentando o diálogo e a troca de experiências que propiciem a elaboração e o compartilhamento de novos modos operatórios; apoio da equipe técnica, por meio de matriciamento, auxiliando em situações mais complexas ou de conflitos; alterações na organização do trabalho, por meio da avaliação de desempenho dos profissionais, adotando-se modelos de gestão que promovam melhorias no trabalho e na saúde do trabalhador.

Ao se realizar uma pesquisa ancorada nessa abordagem epistemológica, busca-se construir um espaço de diálogo e coanálise, individual e coletiva, com os trabalhadores, possibilitando a discussão das experiências individuais e a construção de novos modos de se fazer o trabalho. Ressaltam-se as limitações encontradas nesse estudo, sobretudo com relação ao número de encontros realizados, devido às dificuldades encontradas pelas profissionais para estarem presentes, seja pela não liberação da diretora ou pela própria carga de trabalho - as agendas sempre cheias. Faz-se necessária a realização de um trabalho mais duradouro, com um número maior de encontros, a fim de refinar as discussões e promover uma intervenção pautada na dinâmica compreender $\leftrightarrow$ transformar o trabalho desses profissionais possibilitando mudanças nas práticas cotidianas. Esta pesquisa pode indicar aos profissionais e gestores de saúde possíveis pistas para enfrentarem os desafios propostos pela realidade, de modo a produzirem, em seus cotidianos, saúde entre os trabalhadores.

\section{Referências}

Almeida, R. G. (2011). A ergonomia sob a ótica anglo-saxônica e a ótica francesa. Vértices, 13(1), 115-126. doi: 10.19180/1809-2667.20110007

Boarini, M. L., \& Borges, R. F. (2009). O psicólogo na atenção básica à saúde. Psicologia: Ciência e Profissão, 29(3), 602-613. doi: 10.1590/S1414-98932009000300013

Brito, J., \& Athayde, M. (2003). Trabalho, educação e saúde: o ponto de vista enigmático da atividade. Trabalho, Educação e Saúde, 1(2), 239-266. doi: 10.1590/S1981-77462003000200005

Brito, J., Muniz, H. P., Santorum, K., \& Ramminger, T. (2011). O trabalho nos serviços públicos de saúde: entre a inflação e a ausência de normas. In A. A. Assunção \& J. Brito (Orgs.), Trabalhar na saúde: experiências cotidianas e desafios para a gestão do trabalho e do emprego (pp. 23-43). Rio de Janeiro: Fiocruz.

Cardoso, C. L. (2002). A inserção do psicólogo no Programa Saúde da Família. Psicologia: Ciência e Profissão, 22(1), 2-9. doi: 10.1590/ S1414-98932002000100002

Chiaverini, D. H. (2011). Guia prático de matriciamento em saúde mental. Brasília, DF: Ministério da Saúde, Centro de Estudo e Pesquisa em Saúde Coletiva.

Clot, Y. (2006). A função psicológica do trabalho. Petrópolis, RJ: Vozes. Clot, Y. (2010). Trabalho e poder de agir. Belo Horizonte: Fabrefactum.

Costa, D. F. C., \& Olivo, V. M. F. (2009). Novos sentidos para a atuação do psicólogo no Programa Saúde da Família. Ciência \& Saúde Coletiva, 14(1), 1385-1394. doi: 10.1590/S1413-81232009000800011

Dimenstein, M. D. B. (1998). O psicólogo nas Unidades Básicas de Saúde: desafios para a formação e atuação profissionais. Estudos de Psicologia, 3(1), 53-81. doi: 10.1590/S1413-294X1998000100004

Duarte, L. C. B., \& Moraes, T. D. (2016). Saúde mental de psicólogos atuantes em serviços de atenção primária à saúde. Estudos Interdisciplinares em Psicologia, 7(2), 123-146. doi: 10.5433/2236-6407.2016v7n2p123 
Faïta, D. (2005). Análise dialógica da atividade profissional. Rio de Janeiro: Imprinta Express.

Gomes, R. S. (2009). O trabalho no programa saúde da família do ponto de vista da atividade: a potência, os dilemas e os riscos de ser responsável pela transformação do modelo assistencial (Tese de doutorado). Recuperado de http://bvssp.icict.fiocruz.br/pdf/25485_ Rafael_da_Silveira.pdf

Guérin, F., Laville, A., Daniellou, F., Duraffourg, J., \& Kerguelen, A. (2001). Compreender o trabalho para transformá-lo: a prática da ergonomia. São Paulo: Edgard Blücher.

Jimenez, L. (2011). Psicologia na atenção básica à saúde: demanda, território e integralidade. Psicologia \& Sociedade; 23(n. esp.), 129139. doi: $10.1590 / S 0102-71822011000400016$

Macedo, L. C., Larocca, L. M., Chaves, M. M. N., \& Mazza, V. A. (2008). Análise do discurso: uma reflexão para pesquisar em saúde. Interface - Comunicação, Educação, Saúde, 12(26), 649-657. doi: $10.1590 /$ S1414-32832008000300015
Ministério da Saúde. (2012). Política Nacional de Atenção Básica (Série E. Legislação em Saúde). Brasília: Autor.

Oddone, I., Re, A., \& Briante, G. (1981). Redécouvrir l'expérience ouvrière: vers une autre psychologie du travail? Paris: Éditions Sociales.

Ramminger, T., Athayde, M. R. C., \& Brito, J. (2013). Ampliando o diálogo entre trabalhadores e profissionais de pesquisa: alguns métodos de pesquisa-intervenção para o campo da Saúde do Trabalhador. Ciência e Saúde Coletiva, 18(11), 3191-3202. doi: 10.1590/S1413-81232013001100010

Romagnoli, R. C. (2009). Breve estudo institucionalista acerca do Programa de Saúde da Família. Saúde e Sociedade, 18, 525-536. doi: 10.1590/S0104-12902009000300016

Sales, A. L. L. F., \& Dimenstein, M. (2009). Psicólogos no processo de reforma psiquiátrica: práticas em desconstrução. Psicologia em Estudo, 14(2), 277-285. doi: 10.1590/S1413-73722009000200008

Souza, L.E. P.F. (2014). Saúde pública ou saúde coletiva? Revista Espaço para a Saúde, 15(4), 7-21. doi: 10.22421/1517-7130.2014v15n4p7

Lucas Có Barros Duarte, Mestre em Psicologia pelo Programa de Pósgraduação em Psicologia da Universidade Federal do Espírito Santo. Endereço para correspondência: Universidade Federal do Espírito Santo, Centro de Ciências Humanas e Naturais, Departamento de Psicologia Social e do Desenvolvimento. Av. Fernando Ferrari, $n^{\circ} 514$. Campus Universitário de Goiabeiras, CEP 29075-910 - Vitória, ES Brasil. Telefones: (27) 992333668 / (27) 40092505. Fax: (27) 40092505. E-mail: lucascobarrosduarte@gmail.com

Thiago Drumond Moraes, Doutorado em Psicologia Social pela Universidade do Estado do Rio de Janeiro, Pós-Doutorado pela Aix-Marseille Université, AMU, França, é Professor Adjunto IV no Departamento de Psicologia Social e do Desenvolvimento da Universidade Federal do Espírito Santo e Professor do Programa de Pós-graduação em Psicologia da Universidade Federal do Espírito Santo. E-mail: thiago.moraes@ufes.br

Recebido em 27.Jun.17 Revisado em 29.Mar.18 Aceito em 21.Jun.18 